\title{
Sleep and health
}

\section{Glenn Duns}

Sleep is that golden chain that ties
health and our bodies together.

- Thomas Dekker

The connection between sleep and health has been recognised for centuries, but it is only relatively recently that the study and treatment of sleep disorders has developed as a scientific discipline and medical specialty. ${ }^{1}$ Technological advancements in the 20th century permitted the development of laboratory-based sleep studies that resulted in a much greater understanding of sleep and its disorders. Sleep has come to be viewed as a basic biologic process that affects all organ systems and is necessary for life, a fact that any medical trainee or new parent can confirm, as well as anyone with a longstanding sleep disorder.

Sleep disorders may be associated with a number of serious health consequences, including heart disease, stroke, diabetes, cognitive dysfunction and depression, as described in the articles in this issue of the Australian Journal of General Practice (AJGP). Obstructive sleep apnoea (OSA), a remarkably common sleep disorder with a prevalence of up to $38 \%$, is covered in two complementary articles. The first article, by Hamilton and Chai-Coetzer, details assessment and investigation, including important information on changes to the Medicare Benefits Schedule (MBS) that occurred in November 2018. ${ }^{2}$ General practitioners (GPs) making direct referrals for sleep studies must use approved assessment tools if the studies are to be eligible for MBS rebate, and very useful information about the development and application of these tools is provided in the article. The second article, by Sarkissian et al, provides an update on the current management of OSA. ${ }^{3}$ This includes commonly used devices such as continuous positive airway pressure and mandibular advancement splints, a variety of surgical techniques, and 'future directions' such as hypoglossal nerve stimulation and pharmaceuticals.

Insomnia is another sleep disorder that is common in the general population, and it is also covered in two complementary articles in this issue. Grima et al present diagnostic criteria, theories of insomnia and initial assessment in the first article. ${ }^{4}$ These theoretical models are important in providing a basis for the management of insomnia, as described in the second article. ${ }^{5}$ Most GPs will have encountered patients on long-term sedative hypnotics for the treatment of insomnia. The detailed section describing the evidence base for the use of cognitive behavioural therapy in the treatment of chronic insomnia is of particular interest and provides very useful advice on avoiding long-term benzodiazepine use, as well as methods to wean medication in those who have become dependent.

Sleep disorders can cause sleep deprivation, but there are also many other causes. One vulnerable group is new parents, who may experience long-term sleep deprivation and consequent adverse health consequences. ${ }^{6}$ GPs can play an important part in supporting parents, both as individual patients and by advocating for improved social programs and policies. Another group commonly affected by sleep deprivation is shift workers in general, and healthcare workers in particular - a subject that has received recent media attention. ${ }^{7}$ Shift work is linked to short-term risks such as motor vehicle accidents on the way home from work, ${ }^{8}$ and there is an increased risk of serious or fatal medical errors being made by junior doctors. ${ }^{9}$ Despite these well-documented risks, many doctors continue to work rosters 'that put them at significant and higher risk of fatigue to the extent that it could impact on performance, effect [sic] the health of the doctor and the safety of the patient.' ${ }^{10}$

Sleep is necessary for life and for health. Sleep disorders, disrupted sleep and the associated consequences are common in the general population and are commonly encountered in general practice. The articles in this issue of AJGP aim to provide practical and important information that will help readers repair the 'golden chain' tying health and bodies together, both for themselves and for others.

\section{Author}

Glenn Duns MDCM, FRACGP, MPH, Medical Editor AJGP and general practitioner, Melbourne, Vic

\section{References}

1. Shepard JW, Buysse DJ, Chesson AL Jr, et al. History of the development of sleep medicine in the United States. J Clin Sleep Med 2005;1(1):61-82.

2. Hamilton GS, Chai-Coetzer CL. Update on the assessment and investigation of adult obstructive sleep apnoea. Aust J Gen Pract 2019;48(4):176-81.

3. Sarkissian L, Kitipornchai L, Cistulli P, Mackay SG. An update on the current management of adult obstructive sleep apnoea. Aust J Gen Pract 2019;48(4):182-86.

4. Grima NA, Bei B, Mansfield D. Insomnia theory and assessment. Aust J Gen Pract 2019;48(4):193-97.

5. Grima NA, Bei B, Mansfield D. Insomnia management. Aust J Gen Pract 2019;48(4):198-202.

6. Richter D, Krämer M, Tang N Montgomery-Downs H, Lemola S. Long-term effects of pregnancy and childbirth on sleep satisfaction and duration of first-time and experienced mothers and fathers. Sleep 2019. doi: 10.1093/sleep/zsz015. [Epub ahead of print]

7. Jamie McKinnel. Sydney surgeon quits dream job after seeing 'the dark side' of profession. ABC News. 6 February 2019.

8. Lockley SW, Barger LK, Ayas NT, et al. Effects of health care provider work hours and sleep deprivation on safety and performance. Jt Comm J Qual Patient Saf 2007;33(11 Suppl):7-18.

9. Barger L, Ayas N, Cade B, Cronin J, Rosner B, Speizer F, Czeisler C. Impact of extendedduration shifts on medical errors, adverse events, and attentional failures. PLOS Med 2006 Dec;3(12):e487.

10. Australian Medical Association. Managing the risks of fatigue in the medical workforce 2016: AMA safe hours audit. Barton, ACT: AMA, 2017. 